\title{
Efficacy of endoscopic treatment using double-balloon enteroscopy for postoperative bile leakage in patients with hepaticojejunostomy
}

\section{OPEN}

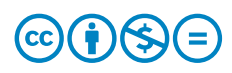

\author{
Authors \\ Kazuyuki Matsumoto, Koichiro Tsutsumi, Hironari Kato, Shigeru Horiguchi, Yosuke Saragai, Saimon Takada, Sho \\ Mizukawa, Shinichiro Muro, Daisuke Uchida, Takeshi Tomoda, Hiroyuki Okada \\ Institution \\ Department of Gastroenterology and Hepatology, \\ Okayama University Graduate School of Medicine, \\ Dentistry, and Pharmaceutical Science, Okayama, Japan \\ Graduate School of Medicine, Dentistry, and \\ Pharmaceutical Science, 2-5-1 Shikata-cho, Okayama \\ 700-8558, Japan \\ Fax: +81-86-235-7219 \\ matsumotokazuyuki0227@yahoo.co.jp
}

submitted 2.7.2017

accepted after revision 27.11.2017

Bibliography

DOI https://doi.org/10.1055/s-0043-125143 |

Endoscopy International Open 2018; 06: E211-E216

(c) Georg Thieme Verlag KG Stuttgart · New York ISSN 2364-3722

Corresponding author

Kazuyuki Matsumoto, MD, PhD, Department of

Gastroenterology and Hepatology, Okayama University

\section{ABSTRACT}

Background and study aims Endoscopic treatment for post-operative bile is technically challenging in patients with altered gastrointestinal anatomy. This study evaluated the effectiveness of using a short-type double-balloon enteroscope to treat postoperative bile leakage after hepaticojejunostomy.

\section{Introduction}

Bile leakage is one of the most common complications after hepatico-biliary surgery, and its incidence has not decreased in recent decades. The efficacy and safety of endoscopic treatment of bile leakage have been reported in patients with normal anatomy [1 - 3]. Recently, a short-type double-balloon enteroscopy-assisted endoscopic retrograde cholangiography (DBEERC) technique was developed in patients with surgically altered gastrointestinal anatomy, which has been used for treatment of several conditions. However, endoscopic treatment of bile leakage in patients with Roux-en-Y or Child's reconstruction is technically challenging, and these patients are usually treated by percutaneous transhepatic biliary drainage (PTBD) or reoperation instead [4-6].

To date, only a few case reports have described the treatment of post-operative bile leakage in patients with altered gastrointestinal anatomy [7-9]. In the current case series, we assessed the effectiveness of DBE-ERC for treatment of postoperative bile leakage in patients with altered gastrointestinal anatomy by retrospectively evaluating their technical and clinical outcomes.

\section{Case Reports}

Eleven consecutive patients with hepaticojejunostomy $(\mathrm{HJ})$ who underwent DBE-ERC for post-operative bile leakage at Okayama University Hospital between September 2010 and August 2016 were retrospectively analysed. Patients with a possible bile leak as determined by radiological studies and/or with increasing bilious output from a transabdominal drain placed during surgery were referred for DBE-ERC. A bile leak was defined as leakage of contrast material from the biliary anastomosis or stump of the bile duct as indicated by fluoroscopy. The Okayama University Hospital institutional review board for human research approved this study.

\section{Treatment for bile leakage with DBE}

DBE-ERC was performed under conscious sedation using intravenous diazepam (5-10 mg) and pethidine hydrochloride (35$140 \mathrm{mg}$ ). A short-type DBE (El-530B, working channel $2.8 \mathrm{~mm}$, working length $1520 \mathrm{~mm}$; Fujifilm, Saitama, Japan, or El-580B, working channel $3.2 \mathrm{~mm}$, working length $1550 \mathrm{~mm}$; Fujifilm) was used. To reach the $\mathrm{HJ}$ anastomosis, a standard push-andpull technique was used throughout the scope insertion with 

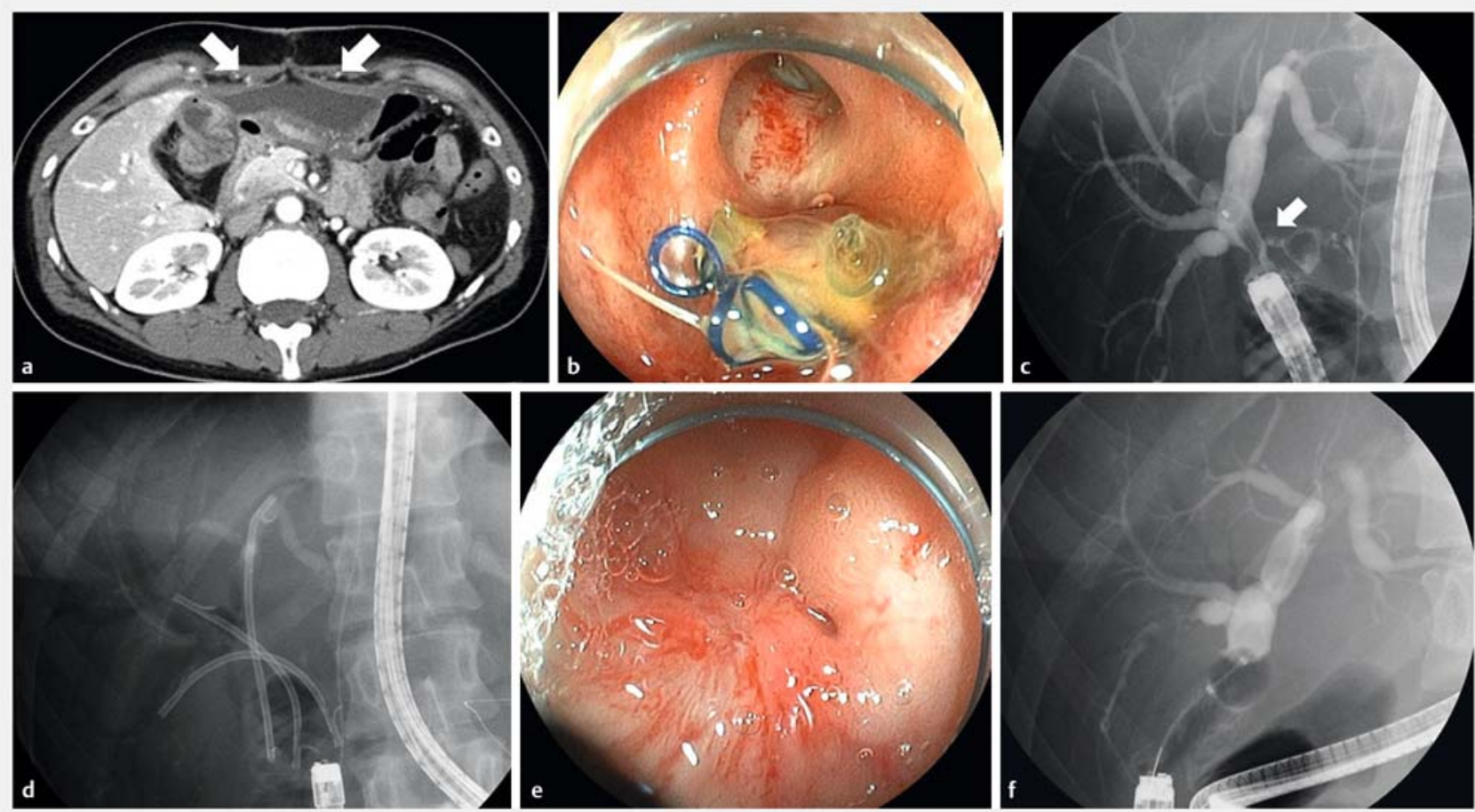

- Fig. 1 a Contrast-enhanced computed tomography (CT) shows extensive fluid collection in the abdomen (patient no. 3). b Endoscopic image of the $\mathrm{HJ}$ site without stricture. Yellow pus can be seen in the area of the site of bile leakage. c Cholangiography showing bile leakage at the anastomosis (arrow). d To lower the intrabiliary pressure and bridge the site of leakage, we deployed three 7-Fr plastic stents at B2, B8, and B6. e At 4-month follow-up, the leakage site is healed with scarring. $\mathbf{f}$ Balloon-occluded cholangiography showed no bile leakage, and the plastic stents were removed.

CO2 insufflation. We usually perform DBE procedures at least 3 weeks after an operation. In these cases, it was difficult to perform PTBD or PTAD, because there was no dilation of the bile duct, and/or no transabdominal roots; therefore, we decided to perform the DBE procedures in consultation with surgery.

We attempted to bridge between the proximal and distal sides of the bile leak with plastic stents to decrease the amount of bile at the leakage site. We inserted multiple plastic stents in the bile duct, if this was possible. The length and type of stent were determined according to the bile leak location. A conventional 7-Fr plastic stent (Though Pass Stent; Gadelius Medical, Tokyo, Japan, or Flexima Stent; Boston Scientific, Tokyo, Japan) was generally used. A 6-Fr stent (Zimmon Stent; Wilson-Cook Medical, Winston-Salem, NC, USA) was used when the bile duct was thin at the proximal side of the bile leak location. When the bile duct proximal to the bile leak location was too thin to place small-bore plastic stents, as in the case of a bile leak from the peripheral duct or cut stump of the liver, the plastic stent was placed at the bile duct on the distal side of the bile leak. When the bile leak location was on the proximal side of the biliary stricture, we placed a plastic stent over the site of the biliary stricture. A typical case of bile leakage at the $\mathrm{HJ}$ anastomosis site treated by DBE-ERC is shown in > Fig. $\mathbf{1}$.

In patients in whom the DBE procedure was not successful, PTBD was performed under abdominal ultrasonographic guidance. Approximately 1 week after PTBD, we attempted to de- ploy a plastic stent using the rendezvous technique, because long-term placement of tubes could result in serious patient discomfort or infection. A guidewire was advanced through the PTBD route from the peripheral bile duct to the HJ anastomosis. At that point, the tip of the guidewire was captured by a snare and retracted into a channel of the DBE. The plastic stent was deployed across the bile leakage site over the guidewire using DBE ( $>$ Fig. 2a, $>$ Fig.2b). After successful stent deployment, we scheduled a follow-up DBE-ERC in 2 to 3 months. DBE-ERC therapy was completed when the bile leak could not be identified after complete filling of the intrahepatic bile duct with contrast agent. After treatment of the bile leakage, we frequently replaced the plastic stent for cases in which biliary stricture was associated with bile leakage. We scheduled a follow-up DBE-ERC and replacement of the plastic stent until resolution of the biliary stricture.

External drainage tubes including the transabdominal drain placed during surgery and/or PTBD tube were removed when the patient's clinical symptoms (such as fever, abdominal pain, and decreasing bilious output from a transabdominal drain) improved after stent deployment. After that, computed tomography or magnetic resonance cholangiopancreatography was performed to check for bile leakage or recurrence of underlying disease every 3 to 6 months or whenever patients reported symptoms. 

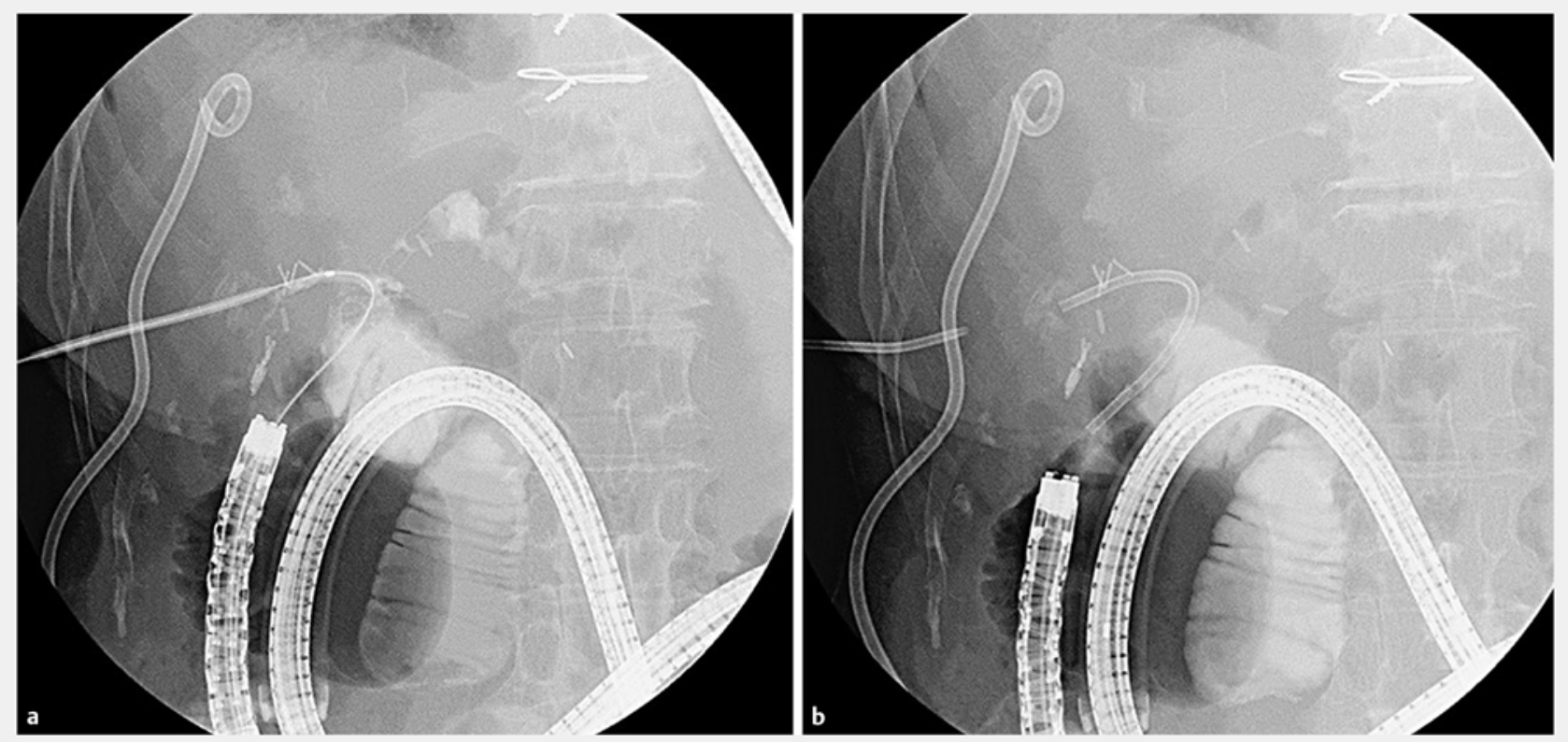

- Fig. 2 a A guidewire was advanced via the PTBD route from the peripheral bile duct to the $\mathrm{HJ}$ anastomosis, and the tip of the guidewire was captured by a snare. Then, the ERC catheter was inserted into the intrahepatic bile duct over the guidewire. $\mathbf{b}$ The plastic stent was successfully deployed with the rendezvous technique.

\section{Definitions and outcome assessments}

Technical success was defined as successful stent placement via either the DBE or rendezvous technique. Adverse events were defined according to the ASGE guidelines [10]. We evaluated patient characteristics, technical and clinical outcomes, adverse events (AEs), and follow-up after DBE treatment including bile leak recurrence.

\section{Results}

\section{Patient characteristics}

- Table 1 summarizes patient characteristics. Eleven patients (7 men; median age 71 years, range $53-74$ years) undergoing DBE-ERC for bile leakage were analyzed. Reconstruction methods were Roux-en $Y$ in 7 patients (64\%) and modified Child's method in 4 (36\%). The location of bile leakage was the anastomosis site in 8 patients $(73 \%)$ and intrahepatic bile duct in 3 (27\%). Two patients (18\%) had stricture at the anastomosis site. The median interval between surgery and the initial DBEERC was 55 days (IQR $43-78$ days).

\section{Treatment for postoperative bile leakage and clinical outcomes after DBE}

- Table 2 and $>$ Table 3 show procedural details and clinical outcomes after DBE-ERC. Scope insertion was successful in all cases and the median insertion time was 16 minutes (interquartile range [IQR], 9-40 minutes). The rate of successful initial stent deployment using only DBE was $64 \%$ (7/11), and the median total procedure time was 62 minutes (IQR, 40-75 minutes). There were no procedure-related complications. PTBD was performed in 4 patients in whom stent deployment failed, of whom 2 patients achieved successful stent deployment using the rendezvous technique. Thus, the overall technical success rate was $82 \%(9 / 11)$.

All patients with successful stent deployment had clinical success, and thereafter the external drainage tube could be removed. In the 7 patients with successful stent placement using only DBE, median time to decrease the amount of bile from the transabdominal drain was 4 days (IQR: 2-10) and for removal of the external drainage tube after internal stenting was 10 days (IQR: $4-18)$. In the 2 patients with successful stent placement using the rendezvous technique, the time to decrease the amount of bile from the transabdominal drain was 6 and 7 days after PTBD, and for removal of the external drainage tube after internal stenting, including the PTBD tube, was 3 and 2 days, respectively. The 2 patients had stricture of the anastomosis, thus internal stent placement was performed. In addition, 7 patients (78\%) achieved internal stent-free status. Median time to stent-free status was 135 days (IQR, 103-252 days), and the median number of DBE sessions was 2 (IQR, $2-3$ sessions). Of the 2 patients with unsuccessful stent deployment using the rendezvous technique, 1 patient was treated successfully with only PTBD, and the external drainage tube could be removed after 226 days. In the other patient, bile leakage could not be controlled without an external tube until death.

During the follow-up period (median 678 days; IQR, $204-$ 1146 days), there was no recurrence of bile leakage in patients who achieved stent-free status. Seven patients died during the follow-up period, 6 due to the primary malignant disease and 1 due to pneumonia. These deaths were not related to bile leakage or cholangitis. 
- Table 1 Baseline characteristics of patients undergoing DBE for bile leakage.

\begin{tabular}{|c|c|c|c|c|c|c|c|c|}
\hline $\begin{array}{l}\text { Pa- } \\
\text { tient } \\
\text { no. }\end{array}$ & Age & Sex & Disease & Surgical method & $\begin{array}{l}\text { Recon- } \\
\text { struction } \\
\text { method }\end{array}$ & $\begin{array}{l}\text { Bile leak } \\
\text { location }\end{array}$ & $\begin{array}{l}\text { Stric- } \\
\text { ture of } \\
\text { anasto- } \\
\text { mosis }\end{array}$ & $\begin{array}{l}\text { Interval be- } \\
\text { tween surgery } \\
\text { and initial DBE } \\
\text { procedure } \\
\text { (days) }\end{array}$ \\
\hline 1 & 74 & $\mathrm{~F}$ & pNET & PPPD & Child's & B1 & no & 15 \\
\hline 2 & 71 & $\mathrm{M}$ & BDCa & $\mathrm{LH}$ & Roux-en-Y & anastomosis & no & 99 \\
\hline 3 & 35 & $\mathrm{~F}$ & CBD & PPPD & Child's & anastomosis & no & 9 \\
\hline 4 & 51 & $\mathrm{M}$ & LC & LDLT (right lobe graft) & Roux-en-Y & anastomosis & no & 57 \\
\hline 5 & 71 & $\mathrm{M}$ & Duodenal adenoma & PPPD & Child's & B6 & no & 127 \\
\hline 6 & 83 & $\mathrm{~F}$ & GBCa & $\mathrm{RH}$ & Roux-en-Y & anastomosis & no & 63 \\
\hline 7 & 70 & $\mathrm{M}$ & PDAC & PPPD & Child's & anastomosis & no & 55 \\
\hline 8 & 75 & $\mathrm{~F}$ & BDCa & EHD resection & Roux-en-Y & anastomosis & yes & 78 \\
\hline 9 & 53 & $\mathrm{M}$ & LC & LDLT (right lobe graft) & Roux-en-Y & anastomosis & yes & 43 \\
\hline 10 & 56 & $\mathrm{M}$ & SFT & Central bisegmentectomy & Roux-en-Y & $\mathrm{B} 2$ & no & 55 \\
\hline 11 & 73 & $\mathrm{M}$ & IPNB & $\mathrm{LH}$ & Roux-en-Y & anastomosis & no & 50 \\
\hline \multicolumn{9}{|c|}{$\begin{array}{l}\text { DBE, double-balloon enteroscopy; pNET, pancreatic neuroendocrine tumour; BDCa, bile duct carcinoma; CBD, congenital biliary dilatation; } \\
\text { LC, liver cirrhosis; GBCa, gallbladder carcinoma; PDAC, pancreatic ductal adenocarcinoma; SFT, solitary fibrous tumour; } \\
\text { IPNB, intraductal papillary neoplasm of the bile duct; PPPD, pylorus-preserving pancreatoduodenectomy; LH, left hepatectomy; } \\
\text { LDLT, living donor liver transplantation; RH, right hepatectomy; EHD, extrahepatic duct }\end{array}$} \\
\hline
\end{tabular}

Table 2 Results of treatment for postoperative bile leakage with DBE-ERC.

\begin{tabular}{|c|c|c|c|c|c|c|c|c|c|}
\hline $\begin{array}{l}\text { Pa- } \\
\text { tient } \\
\text { no. }\end{array}$ & $\begin{array}{l}\text { Scope } \\
\text { insertion }\end{array}$ & $\begin{array}{l}\text { Insertion } \\
\text { time } \\
\text { (min) }\end{array}$ & $\begin{array}{l}\text { Stent de- } \\
\text { ployment }\end{array}$ & Stents & $\begin{array}{l}\text { Total } \\
\text { procedure } \\
\text { time } \\
\text { (min) }\end{array}$ & $\begin{array}{l}\text { Complication } \\
\text { associated } \\
\text { with DBE }\end{array}$ & $\begin{array}{l}\text { Addition- } \\
\text { al inter- } \\
\text { vention }\end{array}$ & $\begin{array}{l}\text { Stent } \\
\text { deployment } \\
\text { (rendezvous } \\
\text { technique) }\end{array}$ & Stents \\
\hline 1 & Success & 10 & Success & 7-Fr PS & 40 & None & - & - & \\
\hline 2 & Success & 7 & Success & $7-\mathrm{Fr} P S \times 3$ & 26 & None & - & - & \\
\hline 3 & Success & 16 & Success & $7-\mathrm{Fr} P S \times 3$ & 47 & None & - & - & \\
\hline 4 & Success & 18 & Success & 7-FrPS & 85 & None & - & - & \\
\hline 5 & Success & 9 & Success & 6-Fr PS & 62 & None & - & - & \\
\hline 6 & Success & 16 & Success & $7-\mathrm{Fr} P S \times 2$ & 75 & None & - & - & \\
\hline 7 & Success & 7 & Success & $7-\mathrm{Fr} P S \times 2$ & 34 & None & - & - & \\
\hline 8 & Success & 82 & Failure & - & 144 & None & PTBD & Success & $7-\mathrm{Fr} P S \times 2$ \\
\hline 9 & Success & 43 & Failure & - & 74 & None & PTBD & Success & $7-\mathrm{Fr} P S \times 2$ \\
\hline 10 & Success & 40 & Failure & - & 60 & None & PTBD & Failure & - \\
\hline 11 & Success & 16 & Failure & - & 75 & None & PTBD & Failure & - \\
\hline
\end{tabular}

DBE-ERC, double-balloon enteroscopy-assisted endoscopic retrograde cholangiography; PS, plastic stent; PTBD, percutaneous transhepatic biliary drainage

\section{Discussion}

The usefulness of endoscopic therapy for postoperative bile leakage has been reported in patients with normal anatomy, such as liver resection without extrahepatic bile duct resection or living donor liver transplantation [1 - 3]. However, only a few case reports have described the use of this technique in patients with altered gastrointestinal anatomy [7-9]. To our knowledge, this is the first case series of the endoscopic treatment of postoperative bile leakage using DBE. 
- Table 3 Clinical outcomes after stent deployment for bile leakage.

\begin{tabular}{|c|c|c|c|c|c|c|c|c|c|}
\hline $\begin{array}{l}\text { Pa- } \\
\text { tient } \\
\text { no. }\end{array}$ & $\begin{array}{l}\text { Removal of } \\
\text { external } \\
\text { drainage tube } \\
\text { after DBE }\end{array}$ & $\begin{array}{l}\text { Time to } \\
\text { decrease } \\
\text { drain volume } \\
\text { (days) }\end{array}$ & $\begin{array}{l}\text { Time to removal of } \\
\text { external drainage } \\
\text { tube after internal } \\
\text { stenting (days) }\end{array}$ & $\begin{array}{l}\text { Total } \\
\text { DBE } \\
\text { ses- } \\
\text { sions }\end{array}$ & $\begin{array}{l}\text { Inter- } \\
\text { nal } \\
\text { stent- } \\
\text { free }\end{array}$ & $\begin{array}{l}\text { Time to } \\
\text { stent- } \\
\text { free } \\
\text { (days) }\end{array}$ & $\begin{array}{l}\text { Follow-up } \\
\text { period } \\
\text { after DBE } \\
\text { (days) }\end{array}$ & $\begin{array}{l}\text { Recur- } \\
\text { rence of } \\
\text { bile leak }\end{array}$ & $\begin{array}{l}\text { Out- } \\
\text { come }\end{array}$ \\
\hline 1 & Success & 14 & 18 & 2 & yes & 135 & 678 & None & Alive \\
\hline 2 & Success & 2 & 7 & 2 & yes & 77 & 129 & None & Death \\
\hline 3 & Success & 2 & 4 & 2 & yes & 137 & 204 & None & Alive \\
\hline 4 & Success & 4 & 7 & 3 & yes & 103 & 854 & None & Alive \\
\hline 5 & Success & 10 & $150^{1}$ & 2 & yes & 252 & 1549 & None & Death \\
\hline 6 & Success & 4 & 13 & 1 & $\mathrm{no}^{2}$ & - & 137 & None & Death \\
\hline 7 & Success & 4 & 10 & 2 & $\mathrm{no}^{2}$ & - & 94 & None & Death \\
\hline 8 & Success & $6^{3}$ & 3 & 3 & yes & 112 & 230 & None & Death \\
\hline 9 & Success & $7^{3}$ & 2 & $12^{4}$ & yes & 1066 & 1146 & None & Alive \\
\hline 10 & Failure $^{5}$ & - & - & 2 & - & - & 2438 & None & Alive \\
\hline 11 & Failure $^{5}$ & - & - & 2 & - & - & 366 & - & Death \\
\hline \multicolumn{10}{|c|}{$\begin{array}{l}\text { Another patient had bile leakage on the second DBE procedure, thus a scheduled stent exchange was performed. } \\
{ }^{1} \text { Patient with liver abscess due to bile leakage } \\
{ }^{2} \text { Patients without stent-free status died due to underlying disease. One patient died before the second DBE procedure. } \\
{ }^{3} \text { The days indicate that the time to decrease the drain drainage volume after PTBD. } \\
{ }^{4} \text { Patient with severe stricture of the anastomosis site. } \\
5 \text { These patients were treated with PTBD }\end{array}$} \\
\hline
\end{tabular}

In a previous report on PTBD therapy for bile leakage after liver resection or living donor liver transplantation, the clinical success rate was $70 \%$ to $91 \%$, with a low $A E$ rate $(0-9 \%)$, and few cases required reoperation (4-9\%) [4-6]. However, longterm placement of tubes can result in serious patient discomfort or infection, which is a drawback of PTBD treatment. Moreover, in cases with no dilatation of the intrahepatic bile duct, PTBD is technically difficult to perform. On the other hand, in reports of endoscopic therapy for treatment of bile leak with normal anatomy, the clinical success rate was about $80 \%$ with a low $\mathrm{AE}$ rate $(0-8 \%)$, but fewer cases required PTBD or reoperation [1 - 3].

In our series, the rate of successful stent deployment using only short-type DBE was $64 \%$ (7/11) among patients with surgically altered anastomosis, all of whom achieved good clinical outcomes. The cause of procedure failure was an upstream bile duct not apparent on ERC imaging due to a large bile leakage from the $\mathrm{H}$ J anastomosis site. Although 4 patients (36\%) required PTBD after failed stent deployment, in 2 of them, successful stent deployment was achieved later using the rendezvous technique. In the 2 patients in whom the rendezvous technique failed, a guidewire could not be advanced through the PTBD route from the peripheral bile duct to the $\mathrm{HJ}$ anastomosis. Consequently, the technical success rate was $82 \%(9 / 11)$, and clinical success was achieved in most patients with successful stent deployment. In a previous report for bile leakage from the $\mathrm{HJ}$ site, placement of an endoscopic nasobiliary (ENBD) tube was an effective bile leakage treatment. In our study, we confirmed the decrease in the amount of bile from the transab- dominal drain after successful stent placement and removed the external drainage tubes. Thus, internal stent placement is also effective for bile leakage from the $\mathrm{HJ}$ site. Considering infection control, placement of the ENBD tube is better than internal plastic stent placement. However, placement of ENBD tubes can result in patient discomfort and has a risk of migration. Although accumulation of further cases is necessary, DBE-ERC may be a favorable option for treatment of bile leakage in cases involving surgical anatomy.

\section{Conclusion}

In conclusion, DBE-ERC was effective in patients experiencing bile leakage after $\mathrm{HJ}$. This procedure allowed more invasive percutaneous or surgical interventions to be avoided.

\section{Competing interests}

None

\section{References}

[1] Dechene A, Jochum C, Fingas C et al. Endoscopic management is the treatment of choice for bile leaks after liver resection. Gastrointest Endosc 2014; 80: 626-633

[2] Yabe S, Kato H, Mizukawa S et al. Predictive factors for outcomes of patients undergoing endoscopic therapy for bile leak after hepatobiliary surgery. Dig Endosc 2017; 29: $353-361$ 
[3] Bhattacharjya S, Puleston ], Davidson BR et al. Outcome of early endoscopic biliary drainage in the management of bile leaks after hepatic resection. Gastrointest Endosc 2003; 57: 526 - 530

[4] Li SQ, Liang LJ, Peng BG et al. Bile leakage after hepatectomy for hepatolithiasis: risk factors and management. Surgery 2007; 141: 340 345

[5] Righi D, Franchello A, Ricchiuti A et al. Safety and efficacy of the percutaneous treatment of bile leaks in hepaticojejunostomy or split-liver transplantation without dilatation of the biliary tree. Liver Transpl 2008; 14: $611-615$

[6] Kim JH, Ko GY, Sung KB et al. Bile leak following living donor liver transplantation: clinical efficacy of percutaneous transhepatic treatment. Liver Transpl 2008; 14: $1142-1149$

[7] Blanco-Velasco G, Blancas-Valencia JM, Hernández-Mondragón OV et al. Treatment of a bile duct leak with ERCP double-balloon entero- scopy in a patient with Roux-en-Y reconstruction. Endoscopy 2016; 48: E197-198

[8] Nagai K, Yane K, Katanuma A et al. Successful less-invasive endoscopic treatment for bile leakage from choledochojejunostomy site using short-type single-balloon enteroscopy. Endoscopy 2016; 48: E140- 141

[9] Gutierrez JP, Smith IB, Wilcox CM et al. Bile leak from the duct of Luschka treated with double-balloon enteroscopy ERCP in a patient with Roux-en-Y gastric bypass. Endoscopy 2013: UCTN: 45: (Suppl. 02): E404

[10] Cotton PB, Eisen GM, Aabakken L et al. A lexicon for endoscopic adverse events; report of an ADGE workshop. Gastrointest Endosc 2010; 71: $446-454$ 